Review

\title{
Population Structure and Genetic Diversity of the Fusarium graminearum Species Complex
}

\author{
Jian-Hua Wang ${ }^{1}$, Mbacke Ndoye ${ }^{1}$, Jing-Bo Zhang ${ }^{1,2}$, He-Ping Li $^{1}$ and Yu-Cai Liao ${ }^{1,2, *}$ \\ 1 Molecular Biotechnology Laboratory of Triticeae Crops, Huazhong Agricultural University, \\ Wuhan 430070, Hubei, China; E-Mails: jianhuawang@webmail.hzau.edu.cn (J.-H.W.); \\ n.mbacke@gmail.com (M.N.); jingbozhang@mail.hzau.edu.cn (J.-B.Z.); \\ hepingli@mail.hzau.edu.cn (H.-P.L.) \\ 2 College of Plant Science and Technology, Huazhong Agricultural University, Wuhan 430070, \\ Hubei, China
}

* Author to whom correspondence should be addressed; E-Mail: yucailiao@mail.hzau.edu.cn or ycliao06@yahoo.com.cn; Tel.: +86-27-87283008; Fax: +86-27-87283008.

Received: 1 June 2011; in revised form: 11 August 2011 / Accepted: 12 August 2011 /

Published: 19 August 2011

\begin{abstract}
The Fusarium graminearum species complex ( $F g$ complex) consists of phylogenetically distinct species some of which cannot be discriminated based on their morphology. Their chemotypes and geographic distributions are dramatically different, and these highlight the challenges that Fusarium head blight (FHB) poses to plant disease specialists and plant breeders, thereby requiring that quarantine officials employ molecular diagnostic tools in their active surveillance programs. Molecular marker technologies play essential roles in species identification of the $F g$ complex, and they are being used widely to assess the genetic diversity of the clade. The utility, applicability and limitations of molecular methods for assessing the population structure and genetic diversity within the $F g$ complex are discussed with suitable examples. Knowledge gained from these studies will provide a baseline for monitoring changes in FHB pathogen diversity and mycotoxin potential over time, both of which are critical to the ultimate control and elimination of this economically devastating disease.
\end{abstract}

Keywords: Fusarium graminearum species complex; chemotype; genetic diversity; population structure; geographic distribution 


\section{Introduction}

Filamentous fungi within the Fusarium graminearum species complex ( $F g$ complex) are the most important etiological agents of Fusarium head blight (FHB) on wheat and other cereal grains worldwide [1-3]. Over the past decade, the $F g$ complex has emerged as one of the most destructive pathogens of cereals resulting in losses valued at billions of dollars to the grain industry [4,5]. Besides reducing yield, these fungi can cause further losses through contamination of crops with mycotoxins such as deoxynivalenol, nivalenol and zearalenone [6,7], which pose a serious threat to animal health and food safety.

Members of the $F g$ complex appear to have evolved allopatrically [8-11]. Biogeographic data suggests that the majority of species within the $F g$ complex have evolutionary origins in the Southern Hemisphere [2,3] and Asia [9]. During recent years, changed agronomy, trade and shipment of cereal commodities, and global climate change have aggravated the spread and severity of FHB northward in China [12-14] and also have resulted in the reemergence of FHB to epidemic levels in the United States, Canada and Europe, causing losses of about \$3 billion for the United States alone between 1998 and 2000 [15,16]. It seems likely that some $F g$ complex species have been introduced into non-indigenous areas relatively recently, especially in areas that rely extensively on agricultural imports [2,3,17-25].

In view of the importance of diseases caused by members of the $F g$ complex, procedures for effective management of these pathogens are urgently needed. In this context, information on the population genetic diversity and dispersal of the $F g$ complex is, consequently, of importance. Various genotypic and phenotypic approaches have been in use over the past few years in research pertaining to the population genetic structure of the $F g$ complex [1,26-33].

This review seeks to outline some of the findings of genetic diversity studies on the $\mathrm{Fg}$ complex that have been conducted over the past two decades. It is not meant to be a comprehensive review of the literature but rather a reflection on some of the common approaches, assumptions, and findings in the field. The genetic diversity, population structure and geographic distribution of the $F g$ complex that have been the focus of these studies will be reviewed. In addition, potential topics for future research will be discussed.

\section{Population Structure and Geographic Distribution of the Fg Complex}

Natural occurrence of the $F g$ complex causing FHB on cereal crops have been reported in different continents, e.g., Africa [11,34-37], America [3,4,7,17,20,25,33,38-49], Asia [9,13,14,17,21-24,28,30,50-57], Europe [50,58-60], and Oceania [18,61-64]. Members of the $\mathrm{Fg}$ complex were considered a single cosmopolitan species, due to the failure of morphological species recognition to accurately assess species limits for this group. O’Donnell et al. [1] first identified seven phylogenetic lineages within the $F g$ complex, employing genealogical concordance phylogenetic species recognition (GCPSR) [65]. Most recently, employing a high-throughput multilocus genotyping (MLGT) assay of portions of 13 housing keeping genes, combined with GCPSR and molecular marker technologies, 13 phylogenetically distinct, cryptic species have been identified within the Fg complex [1-3,9,11]. The species designation Fusarium graminearum will therefore be sensu stricto, 
and other $F g$ complex species designations will be used. These 13 species include: $F$. austroamericanum, F. meridionale, F. boothii, F. mesoamericanum, F. acaciae-mearnsii, F. asiaticum, F. graminearum sensu stricto, F. cortaderiae, F. brasilicum, F. gerlachii, F. vorosii, $F$. aethiopicum, and $F$. ussurianum [1-3,9,11]. In addition, a putative new species within the Fg complex was identified in Nepal by Chandler et al. [10] and later characterized by Desjardins and Proctor [66] as the "Nepal lineage".

A biogeographic hypothesis suggests that the basal most species within the $F g$ complex may be endemic to the southern hemisphere while the derived species evolved within the northern hemisphere [3]. According to the surveys to date, F. austroamericanum, $F$. meridionale, F. cortaderiae, and F. brasilicum appear to be endemic to South America [3,46]; F. acaciae-mearnsii to Australia or less likely Africa [2]; F. asiaticum, F. vorosii and F. ussurianum to Asia [2]; F. aethiopicum to Africa [11]; F. boothii and F. mesoamericanum to Central America [2,11]; F. gerlachii to the US [3].

In the surveys conducted worldwide to date, $F$. graminearum sensu stricto ( $F$. graminearum s.s.) is cosmopolitan in distribution and has been found in Asia, Africa, America, Europe, and Oceania, while another species, $F$. asiaticum, is widespread in Asia [1,2,59,41,66,54]. FHB was initially reported in 1936 in China, and since then FHB epidemics have become more severe and frequent in the middle and lower regions of the Yangtze River, and in Heilongjiang province in northeastern China [12]. More recently FHB frequently occurs in areas along the Yangtze River, a region with conditions favorable for infection by the pathogen [13,14,21-24]. F. asiaticum is the predominant species in this region [13,14,30,21-24]. Based on the climate data of 30 y during 1970-1999, our group assayed the geographical distribution patterns of $F$. graminearum s.s. and $F$. asiaticum in China. Our results indicated that $F$. graminearum s.s. was mainly obtained from cooler regions where the annual average temperature was $15{ }^{\circ} \mathrm{C}$ or lower. In contrast, $95 \%$ of $F$. asiaticum isolates were collected from warmer regions [14,21]. These results suggest ecological factors may have had a significant effect on the distribution of these species $[13,14,46,51,54,66]$. In Japan, $F$. graminearum s.s. and $F$. asiaticum are the predominant species, with $F$. asiaticum predominating in the southern regions as in China [52]. A preliminary report of the $F$. graminearum clade isolated from maize in Korea indicated that F. graminearum s.s. was dominant, accounting for $74 \%$ of strains, while three additional species, F. meridionale, F. boothii, and F. asiaticum, were also present at low frequencies [67]. However, $F$. asiaticum, F. meridionale and F. boothii were the major causal agents of Gibberella ear rot of maize in Nepal, whereas F. graminearum s.s., which dominates in maize elsewhere in Asia and worldwide, was not detected [66]. Similarly, F. meridionale and F. boothii play a substantial role in the infection and trichothecene contamination of maize in Argentina. F. graminearum s.s. was not represented among the isolates examined [46]. In contrast, a previous survey of the $F g$ complex collected from wheat in the center of Argentina identified all 113 isolates as F. graminearum s.s. [41]. In Korea, 80\% of the isolates collected from rice belonged to $F$. asiaticum, which is dramatically different from the results on maize [54]. Although the underlying factors for species distribution are unknown, the occurrence of $F$. asiaticum in Louisiana closely overlaps with rice-growing areas in Louisiana [25]. 


\section{Chemotype Distribution of the Fg Complex}

Every species within the $F g$ complex is capable of producing type B trichothecenes in planta [11]. Based on the chemical structure, including the acetylation position, three type B trichothecene chemotypes have been identified within the $F g$ complex: deoxynivalenol and 3-acetyldeoxy-nivalenol (3-AcDON), deoxynivalenol and 15-acetyldeoxynivalenol (15-AcDON), and nivalenol and 4-acetylnivalenol (NIV) [32,68,69].

In the limited surveys to date, strains of several newly discovered species were found to represent only a single chemotype: 3-AcDON for the F. ussurianum strains [9], 15-AcDON for F. aethiopicum, $F$. boothii and $F$. vorosii strains [3,9,11,20,70], and NIV for $F$. meridionale and $F$. gerlachii strains [3,11,20,46,70]. 3-AcDON, 15-AcDON and NIV producers were identified in both $F$. graminearum s.s. and $F$. asiaticum. The remaining 5 species, $F$. acaciae-mearnsii, F. mesoamericanum, F. austroamericanum, F. cortaderiae, and $F$. brasilicum can produce both 3-AcDON and NIV [20].

Dramatic differences in the geographic distribution of $F g$ complex chemotypes were reported by Gale et al. [30], Zhang et al. [21] and Qu et al. [13] in China, and by Karugia et al. [56] in Japan. Results of these surveys show that Chinese populations of F. graminearum s.s. on wheat and barley produce $15-\mathrm{AcDON}$ predominately or exclusively, in contrast to populations of $F$. asiaticum, which predominately produce 3-AcDON or NIV. While in Japan, out of a total of $179 \mathrm{~F}$. asiaticum isolates, 80 isolates were of the NIV chemotype, and the remaining 99 isolates were of 3-AcDON producers [56]. NIV chemotype was predominant among the $F g$ complex strains isolated from Korean rice $[54,57]$. In contrast, the predominant chemotype among the corn isolates varied according to geographic region [57]. In Nepal, NIV producers of the $F g$ complex were isolated more than twice as frequently as DON producers from maize seed samples [66,71].

Direct competitive enzyme-linked immunosorbent assay (ELISA) indicated that $75 \%$ of grain samples from Kenya were contaminated with DON [35]. Eleven Fusarium-related mycotoxins were quantified by chemical analysis, the results demonstrated that DON was detected at the highest frequency (69\%) [36]. The trichothecene chemotype of 560 South African isolates of the $F g$ complex collected from diseased wheat, barley and maize were determined using MLGT assay. The results showed that 535 isolates possessed the 15-AcDON chemotype, 22 isolates represented the NIV chemotype, and only 3 isolates were of the 3-AcDON chemotype [37]. F. aethiopicum, a novel species reported only from Ethiopia, belonged to 15 -AcDON chemotype [11,37].

In the surveys conducted to date in Europe, the 15-AcDON chemotype of the Fg complex was the predominant, followed by the 3-AcDON chemotype and a few isolates of the NIV chemotype. For example, in UK [72], Germany [73], and Luxembourg [74], the 15-AcDON chemotype represented more than $90 \%$ of the population, and DON producers also were in high portion in Netherlands [58]. In New Zealand, however, Lauren et al. [62] and Monds et al. [18] found that among the F. graminearum s.s. strains, NIV chemotypes were as common as DON chemotypes, with the DON chemotypes producing primarily $15-\mathrm{AcDON}$. All the isolates of $F$. cortaderiae, the other $F g$ clade species found in New Zealand, were NIV producers [18].

Previous studies indicated that $F$. graminearum s.s. isolates with a $15-\mathrm{AcDON}$ chemotype represented the predominant cause of FHB in North America $[68,75,76]$. However, a significant increasing 
frequency of 3-AcDON chemotype from west to east occurred in Canada in the last decade [20,77]. Schmale et al. [78] evaluated the trichothecene genotypes of 998 Gibberella zeae (G. zeae) isolates gathered from 39 winter wheat fields in the eastern US, and found that $92 \%$ percent of the isolates were 15-AcDON, 7\% were 3-AcDON, and $1 \%$ was NIV, with an increasing trend of 3-AcDON producers from south to north. Starkey et al. [3] identified 2 NIV-chemotype isolates (NRRL 38371 and NRRL 38383) within 6 F. graminearum s.s. strains in Louisiana. A recent survey by Gale et al. [25] suggests that NIV-type F. graminearum s.s. populations represented a high proportion (79\%) of isolates in Louisiana. It was suggested that the NIV chemotype of F. graminearum s.s. was rare in the United States, and that the only way for the NIV chemotype with adequate fitness to become established in North America would be by migration and introgression into the resident DON populations [71]. In addition, chemotype variation has been maintained by natural selection and appears to have adaptive potential for FHB pathogens [32].

In Argentina, within the Fg complex strains, 15-AcDON chemotype was the most common [44,47], and trichothecene chemotype diversity among the isolates examined was directly tied to species differences [46]. Two studies of the wheat kernel samples in southern Brazil showed that 15-AcDON chemotype was predominant ( $>92 \%$ ), followed by the NIV chemotype, and no 3-AcDON chemotype was observed [43,49]. A recent survey of barley grain samples revealed that, $4 \%$ of the strains were 3 -AcDON chemotype, $66 \%$ were 15 -AcDON chemotype and $29 \%$ were NIV chemotype [48].

Broad geographic surveys for trichothecene chemotype of the $F g$ complex from cereal crops are important to establish baselines for these genotypes against which any future shifts in populations can be assessed [3,20,25,42,77,78].

\section{Molecular Markers for Fg Complex Genetic Analyses}

High genotypic diversity has been revealed within the $F g$ complex, even within a species [30,33,38,56,79,80], using molecular markers. Molecular markers such as sequence characterized amplified regions (SCAR), single strand conformational polymorphism (SSCP), randomly amplified polymorphic DNA (RAPD), amplified fragment length polymorphism (AFLP), restriction fragment length polymorphism (RFLP), sequence related amplified polymorphism (SRAP), single nucleotide polymorphism (SNP), and variable number of tandem repeat (VNTR) have been used extensively to study genetic variability of the $F g$ complex. Recently, a high resolution, SNP-based multilocus genotyping assay was used in numerous investigations of diversity within the $F g$ complex, and several novel species have been identified.

\subsection{SCAR (Sequence Characterized Amplified Regions) or SSCP (Single Strand Conformational Polymorphism)}

SCAR analysis using Fg16F/R primer was previously used to distinguish $F$. graminearum s.s. and $F$. asiaticum isolates from China [14]. However, differentiation of $F$. asiaticum from $F$. meridionale on the basis of SCAR fragment size was not reliable because the Fg16F/R amplicon size is identical (497 bp) [29]. However, because the sequence of the $F$. meridionale and $F$. asiaticum amplicons differ, single-strand conformational polymorphism (SSCP) enabled unequivocal resolution of $F$. meridionale from $F$. asiaticum [13]. 
SSCP analysis of the Fg16F/R PCR amplicon differentiated F. graminearum s.s., F. asiaticum and F. meridionale from China and revealed three haplotypes among sequence-characterized amplified region (SCAR) type $1 F$. graminearum s.s. isolates: $1 \mathrm{~A}, 1 \mathrm{~B}$ and $1 \mathrm{C}$, while the remaining SCAR types displayed the same SSCP patterns with no polymorphism [13]. All the F. graminearum s.s. isolates from China and Europe, and 5 of the seven isolates from the US were haplotype 1A. The remaining two American isolates (A2 and A5) were haplotype 1B [13]. DNA sequencing of the Fg16F/R product confirmed that haplotype $1 \mathrm{~B}$ differed from that of $1 \mathrm{~A}$ at nucleotide 348 (C-T) and 412 (T-A) [81]. SSCP assays of a further 440 isolates from China indicated that 90 were $F$. graminearum (haplotype 1A) and 350 were $F$. asiaticum (haplotype 5) with no polymorphism within the species [81]. This high level of uniformity contrasts markedly with isolates from elsewhere. For example, three haplotypes (haplotypes 3, 4 and 5) were observed among $F$. asiaticum isolates from Nepal [29], while two haplotypes were observed among the limited number of isolates from Europe (haplotypes 1A and 6) and the US (haplotypes $1 \mathrm{~A}$ and $1 \mathrm{~B}$ ).

Investigators have used a variety of methods to improve the resolving power of SSCP, however, differentiation among polymorphic molecules on a polyacrylamide matrix is not entirely predictable, and the method can result in false negatives, ambiguous results and experimental artifacts. The low haplotype diversity detected by the SSCP markers indicates that it is too conserved for population genetic studies of the $\mathrm{Fg}$ complex [14].

\subsection{RAPD (Randomly Amplified Polymorphic DNA)}

RAPD technique is a PCR procedure involving very short (10 or fewer bases) arbitrary primers at a low annealing temperature $\left(30-38{ }^{\circ} \mathrm{C}\right)$. RAPD analysis detects two types of genetic variation: (i) in the length of DNA between the two primer binding sites; and (ii) in sequence variation at the priming regions. When the amplified products from such a reaction are analyzed on an electrophoresis gel, unique banding patterns are seen. These patterns may reflect the differences characteristic of certain species or strains. The RAPD method is simple, sensitive, rapid and has been used for distinguishing several pathogens [82]. A high level of genotypic diversity in $F g$ complex isolates in Canada, via RAPD markers, was demonstrated by Dusabenyagasani et al. [83], and $90.56 \%$ of the genetic variability was explained by within-region variation. RAPD analysis of 42 isolates, which originated from northwest Europe, the US and Nepal, identified three groups, two of which contained the isolates from Nepal, and a third contained the isolates from Europe and the US [29]. A considerable genetic resemblance was found by RAPD between 34 isolates from northeastern and northwestern China. The isolate grouping was not related to pathogenicity or to host cultivar [84]. Similar findings were obtained in the US, where F. graminearum s.s. is the predominant FHB species [3,38,42]. However, relatively low amount of genetic diversity were revealed using RAPD analysis of isolates in Canada [85] and Brazil [86].

RAPD has the major disadvantage that it is very sensitive to the reaction conditions, DNA quality and PCR temperature profiles [87], which limits its application. This problem can be minimized if strains under study are treated identically. RAPD has been criticized for lack of reproducibility [88]. 


\subsection{AFLP (Amplified Fragment Length Polymorphism)}

AFLP is a DNA fingerprinting technique that detects genomic restriction fragments and thus resembles the RFLP technique. The method allows for the specific co-amplification of high numbers of restriction fragments. Typically 50-100 restriction fragments are amplified and detected on denaturing polyacrylamide gels.

The advantage of AFLP over other techniques is that multiple bands are derived from all over the genome. This prevents overinterpretation or misinterpretation due to point mutations or single-locus recombination, which may affect other genotypic characteristics. Different enzymes and/or selective extension nucleotides can be used to create new sets of markers. Therefore, AFLP can provide an almost limitless set of genetic markers, and as many as 50-75 AFLP markers can be resolved per reaction [89]. The AFLP markers showed a higher degree of resolution for discriminating closely related fungi. In Fusarium taxonomy, AFLP was first applied to discriminate between different strains of the $F g$ complex [90]. It was used for assessing the population structure of the $F g$ complex and identified considerable diversity within the clade [14,91-93]. Bowden et al. [94] using AFLP analysis to determine genetic diversity in the $F g$ complex from Kansas and North Dakota, found a high degree of homogeneity between subpopulations. The analysis of 59 isolates from Australia by AFLP showed that 56 isolates had distinct haplotypes, and the spatial diversity within the $F$. graminearum s.s. strains was high within a single field [63]. The AFLP analysis by Monds et al. [18] showed that the $F g$ complex was represented by $F$. graminearum s.s. and $F$. cortaderiae in New Zealand, and that these two species originated from at least two regions, and probably on at least two hosts. More diversity of the $F g$ complex was detected by AFLP analysis of populations from Europe, the US or Nepal [14]. Based on AFLP analyses, 270 bands were detected among $333 F$. asiaticum isolates from the five populations in Korea, and $36 \%$ of the AFLP bands were polymorphic [54]. Among the 270 multilocus haplotypes, 225 were represented by a single strain, and 45 haplotypes were detected more than once. Genotypic diversity varied by population, and the number of polymorphic loci in an individual population ranged from 32 to 56 [54]. A sample of 103 F. graminearum s.s. isolates from Brazil were assessed employing AFLP. Astolfi et al. [49] found that isolates with the same haplotype were rare and genotypic diversity was uniformly high $(\geq 98 \%$ of the count) in all three subpopulations analyzed.

In our experience, AFLP is not highly reproducible. When controlled experiments are conducted over $10 \%$ of the bands are not reproduced. Also scoring band size is exceedingly difficult. Besides, alleles are not easily recognized [95], even when a capillary DNA sequencer is employed [96].

\subsection{SRAP (Sequence Related Amplified Polymorphism)}

Sequence-related amplified polymorphism (SRAP) is a novel molecular marker technique based on two-primer amplification that preferentially amplifies open reading frames (ORFs) [97]. The forward primers preferentially amplify exonic regions, and the reverse primers preferentially amplify intronic regions and regions with promoters. The observed polymorphism originates in the variation in the length of these extrons, introns, promoters, and spacers, both among individuals and among species [97]. With this unique primer design, SRAP markers are more reproducible, more stable, and less complex 
than RAPD and AFLPs. This technique has been used to investigate genetic diversity of the $F g$ complex in Canada [40]. SRAP results are in agreement with findings of high diversity of the $F g$ complex isolates from the United States and eastern Canada based on RAPD and AFLP markers [98]. It could help to assess whether different management practices affect the genetic diversity of the $\mathrm{Fg}$ complex populations [98].

The disadvantage of this technique is that both dominant and co-dominant markers can be produced which makes the interpretation of the data a little bit more complicated.

\subsection{SNP (Single Nucleotide Polymorphism)}

A SNP is a single base pair mutation at a specific locus, usually consisting of two alleles that can be amplified by two pairs of primers in one PCR reaction. Cuomo et al. [99] identified more than 10,000 SNPs from a comparison of two $F$. graminearum s.s. strains (strains PH-1 and GZ3639), which were frequently located near telomeres and within other discrete chromosomal segments. $F$. graminearum genes specifically expressed during plant infection (including predicted secreted proteins, major facilitator transporters, amino acid transporters, and cytochrome P450s) are all overrepresented in high SNP density regions, which may allow the fungus to adapt rapidly to changing environments or hosts. Perhaps the SNP have the greatest potential in elucidating the dynamics of host pathogen interactions.

Yang et al. [22] characterized Fusarium isolates at the species level by a robust set of diagnostic primers based on SNPs among members of the $F g$ complex. In addition, numerous SNPs-based trichothecene chemotype assays were developed from the trichothecene biosynthetic pathway genes. Two sets of multiplex primers specific to individual chemotypes were designed from the Tri3 and Tri12 genes [20,32]. Both multiplex assays were widely used to predict the chemotype of the Fg complex strains [3,25,43,48,49,78,100]. Primers derived from the Tri13 and Tri7 genes [10,58], which are responsible for the oxygenation and acetylating of the C-4 atom of the trichothecene molecule [101], were used to discriminate between DON and NIV producers [10,43,51,53,58,72,100]. The primer pairs Tri303F/R and Tri315F/R derived from the Tri3 gene is used to predict if a DON chemotype is a $3-A c D O N$ or $15-A c D O N$ producer [21,51,72]. Very recently, Zhang et al. [23] also developed an effective set of diagnostic primers based on SNPs among three different chemotype isolates and determined that there was a recent shift to the 3-AcDON chemotype. The high genetic diversity of this group of genes suggests that the fungus has great capacity for adaptability and genetic change during its interaction with a host species. The richness in SNPs in the fungal genome combined with real-time PCR assays would provide a powerful tool for development of markers for various identifications within the $F g$ complex.

\subsection{VNTR (Variable Number of Tandem Repeat)}

VNTR markers have been developed for $F g$ complex species and have been effectively used for population analyses $[20,55,70,102]$. VNTR may be more desirable than RFLP markers for population genetic analysis due to their ability to generate accurate polymorphic data and due to their codominance. Generally, the development of VNTR markers is costly and burdensome and therefore few VNTR markers have been reported to date for the $F g$ complex [102,103]. A relative small genome 
size, 36.1 Mb, of F. graminearum s.s. (strain PH-1, NRRL 31084) sequenced recently by the Center for Genome Research, Cambridge, MA, USA [99], may carry a low level of variation within tandem repeat sequences in the genome. However, the availability of the whole genome sequence may allow a bioinformatic approach for the further development of VNTR markers in these species. Zhang et al. [23], using seven highly informative VNTR markers on $448 F$. asiaticum isolates from Chinese barley, showed a significant degree of population subdivision $(P<0.001)$ among populations from the upper, middle, and lower valleys of the Yangtze River, with little gene flow ( $N m=1.210)$. A comprehensive VNTR analysis of $1106 \mathrm{~F}$. asiaticum isolates collected from western China, centre and eastern provinces, indicated that the genetic diversity of the species showed a clear substructure even within provinces [24]. Ten VNTR markers were used to determine the genetic diversity of an older population ( $n=115$ isolates) of $G$. zeae collected from 1997 to 2000 with a newer population ( $n=147$ isolates) collected in 2008. High gene diversity and genotypic diversity were revealed, but the linkage disequilibrium were low in both populations, and the differentiation between the two populations was low [100].

\subsection{RFLP (Restriction Fragment Length Polymorphism)}

The RFLP method is used to assess the extent of natural variation or relatedness in the genomes of different species, biotypes, strains or races of fungal pathogens. Deletions or insertions in the DNA sequences may lead to variation (polymorphisms) in fragment sizes. The sensitivity and reliability of the assay may be enhanced by employing highly repetitive DNA sequences as probes, as the signal is present in multiple copies.

Members of the $F g$ complex and $F$. pseudograminearum are morphologically very similar, and were previously designated Group 1 and Group 2 of F. graminearum [104]. RFLP [105], DNA sequence [106], and isozyme [107] data indicated that these two groups were phylogenetically distinct and should be regarded as separate species. RFLP analysis of the $\mathrm{Fg}$ complex collected from eastern China showed a population mean gene diversity of $30.6 \%$ to $36.4 \%$ and identified 65 distinct haplotypes among 225 isolates [30].

An alternative PCR-RFLP marker system based on single-copy nuclear polymorphic (SCNP) sequences in $F g$ complex was developed [25]. These markers can be useful when VNTR analysis is technologically not possible, mutation rates differ, or selective neutrality is a concern [25]. This method not only substantially reduced screening time and cost but also allowed for the strategic positioning of markers across the whole genome. Based on the moderate number of alleles per locus and the low number of shared genotypes, this PCR-RFLP system allows for excellent genotypic resolution without excessive polymorphisms [25]. Therefore it is suitable for population level analysis of the $F g$ complex in the future.

\subsection{GCPSR (Genealogical Concordance Phylogenetic Species Recognition) and MLGT(Multilocus Genotyping Assay)}

GCPSR was first used to investigate species diversity within the $F g$ complex by O'Donnell et al. [1]. A global collection of FHB strains were investigated by Ward et al. [32], O'Donnell et al. [2], and Starkey et al. [3], phylogenetic analyses of DNA sequences from portions of 13 independent loci, 
including translation elongation factor $(E F-1 \alpha), \alpha$-tubulin $(\alpha-t u b), \beta$-tubulin $(\beta-t u b)$, histone H3 (HIS), phosphate permease $(P H O)$, reductase $(R E D)$, trichothecene 3-O-acetyltransferase (Tri101), ammonium ligase (URA), ITS/28S rDNA locus, and four adjacent mating-type (MAT) genes (MAT1-1-3, MAT1-1-2, MAT1-1-1, and MAT1-2-1) plus the corresponding intergenic regions (A, B, and C), totaling $16.33 \mathrm{~kb}$, provided strong evidence that this morphologically defined species comprises at least 13 phylogenetically distinct species.

MLGT was developed by Ward et al. [20]. Forty-one oligonucleotide probes targeting species or trichothecene chemotype-specific variation within 6 genes were developed base on SNPs [20], which facilitated the species and chemotype assays of the $F g$ complex. Based on the MLGT assays, two novel species within the $F g$ complex, F. aethiopicum [11] and $F$. ussurianum [9], were recently identified in Ethiopia and the Russian Far East, respectively. Four novel probes, 2 for $F$. aethiopicum and 2 for F. ussurianum, were developed from variation identified in the Tril01 and RED genes for identification of these two species [9,11]. MLGT is based on direct interrogation of SNPs. It provides a rapid, efficient and accurate framework for studies to understand the population dynamics, trichothecene chemotype distribution, and ecology of the Fg complex [9,11,20,25,37,45].

\section{Conclusions}

Members of the $F g$ complex were thought to represent the single species $F$. graminearum (teleomorph G. zeae) [11]. Thus multiple $F g$ complex were reported under the name $F$. graminearum in previous studies. Morphological variation within the $F g$ complex is insufficient for discerning species identity. However, by employing GCPSR, a MLGT assay, and different molecular marker technologies, 13 phylogenetically distinct species have been identified within the $\mathrm{Fg}$ complex $[1-3,9,11,65]$. These findings indicate that diversity within the $F g$ species complex is much greater than previously believed [46].

As FHB is a serious threat to cereal production worldwide, information on the global distribution, aggressiveness, and toxin accumulation of $F g$ complex strains will be critical to identifying and implementing pathogen control strategies. Some updated molecular marker technologies, such as VNTR and PCR-RFLP, will play an important role in population genetic analyses of the $F g$ complex. The increasing database of global surveillance information is providing a detailed understanding of the geographic distribution, host range, aggressiveness, epidemiology, and evolutionary dynamics of the FHB pathogens and their toxin potential, all of which are critical for monitoring changes in this economically devastating disease worldwide [11].

\section{Acknowledgments}

This work was supported by the National Basic Research Program of China (2009CB118806), the National Natural Science Foundation of China (30571160, 30771337), the Ministry of Agriculture of China (2008ZX08002-001, 2009ZX08002-001B), and the Ministry of Education of China (20090146120013). The authors are thankful for a Doctorial fellowship from the Chinese Exchange program (to M.N.). 


\section{Conflict of Interest}

The authors declare no conflict of interest.

\section{References}

1. O’Donnell, K.; Kistler, H.C.; Tacke, B.K.; Casper, H.H. Gene genealogies reveal global phylogeographic structure and reproductive isolation among lineages of Fusarium graminearum, the fungus causing wheat scab. Proc. Natl. Acad. Sci. USA 2000, 97, 7905-7910.

2. O’Donnell, K.; Ward, T.J.; Geiser, D.M.; Kistler, H.C.; Aoki, T. Genealogical concordance between mating type locus and seven other nuclear genes supports formal recognition of nine phylogenetically distinct species within the Fusarium graminearum clade. Fungal Genet. Biol. 2004, 41, 600-623.

3. Starkey, D.E.; Ward, T.J.; Aoki, T.; Gale, L.R.; Kistler, H.C.; Geiser, D.M.; Suga, H.; Tóth, B.; Varga, J.; O'Donnell, K. Global molecular surveillance reveals novel Fusarium head blight species and trichothecene toxin diversity. Fungal Genet. Biol. 2007, 44, 1191-1204.

4. Clear, R.M.; Patrick, S.K. Fusarium head blight pathogens isolated from Fusarium-damaged kernels of wheat in western Canada, 1993 to 1998. Can. J. Plant Pathol. 2000, 22, 51-60.

5. Windels, C.E. Economic and social impacts of Fusarium head blight: Changing farms and rural communities in the northern great plains. Phytopathology 2000, 90, 17-21.

6. Snijders, C.H.A. Fusarium head blight and mycotoxin contamination of wheat, a review. Eur. J. Plant Pathol. 1990, 96, 187-198.

7. Tuite, J.; Shaner, G.; Everson, R.J. Wheat scab in soft red winter wheat in Indiana in 1986 and its relation to some quality measurements. Plant Dis. 1990, 74, 959-962.

8. Giraud, T.; Refregier, G.; Gac, I.L.; De Vienne, D.M.; Hood, M.E. Speciation in fungi. Fungal Genet. Biol. 2008, 45, 791-802.

9. Yli-Mattila, T.; Gagkaeva, T.; Ward, T.J.; Aoki, T.; Kistler, H.C.; O’Donnell, K. A novel Asian clade within the Fusarium graminearum species complex includes a newly discovered cereal head blight pathogen from the Russian Far East. Mycologia 2009, 101, 841-852.

10. Chandler, E.A.; Simpson, D.R.; Thomsett, M.A.; Nicholson, P. Development of PCR assays to Tri7 and Tri13 trichothecene biosynthetic genes, and characterisaton of chemotypes of Fusarium graminearum, Fusarium culmorum and Fusarium cerealis. Physiol. Mol. Plant Pathol. 2003, 62, 355-367.

11. O’Donnell, K.; Ward, T.J.; Aberra, D.; Kistler, H.C.; Aoki, T.; Orwig, N.; Kimura, M.; Bjornstad, A.; Klemsdal, S.S. Multilocus genotyping and molecular phylogenetics resolve a novel head blight pathogen within the Fusarium graminearum species complex from Ethiopia. Fungal Genet. Biol. 2008, 45, 1514-1522.

12. Chen, L.F.; Bai, G.H.; Desjardins, A.E. Recent Advances in Wheat Head Scab Research in China. In Proceedings of the International Symposium on Wheat Improvement for Scab Resistance, Suzhou and Nanjing, Jiangsu, China, 2000; Raupp, W.J., Ma, Z., Chen, P., Liu, D., Eds.; pp. 258-273. Available online: http://www.nal.usda.gov/pgdic/WHS/whsindex.html (accessed on 15 August 2011). 
13. Qu, B.; Li, H.P.; Zhang, J.B.; Xu, Y.B.; Huang, T.; Wu, A.B.; Zhao, C.S.; Carter, J.; Nicholson, P.; Liao, Y.C. Geographic distribution and genetic diversity of Fusarium graminearum and F. asiaticum on wheat spikes throughout China. Plant Pathol. 2008, 57, 15-24.

14. Qu, B.; Li, H.P.; Zhang, J.B.; Huang, T.; Carter, J.; Liao, Y.C.; Nicholson, P. Comparison of genetic diversity and pathogenicity of Fusarium head blight pathogens from China and Europe by SSCP and seedling assays on wheat. Plant Pathol. 2008, 57, 642-651.

15. Nganje, W.E.; Johnson, D.D.; Wilson, W.W.; Leistritz, F.L.; Bangsund, D.A.; Tiapo, N.M. Economic Impacts of Fusarium Head Blight in Wheat and Barley: 1998-2000. In Proceedings of Agribusiness and Applied Economics Report, North Dakota State University, Fargo, ND, USA, 2001; pp. 1-41. Available online: http://ageconsearch.umn.edu/bitstream/23515/1/aer464.pdf (accessed on 15 August 2011).

16. Nganje, W.E.; Bangsund, D.A.; Leistritz, F.L.; Wilson, W.W.; Tiapo, N.M. Estimating the Economic Impact of a Crop Disease: The Case of Fusarium Head Blight in U.S. Wheat and Barley. In National Fusarium Head Blight Forum Proceedings, Okemos, MI, USA, 2002; Canty, S.M., Lewis, J., Siler, L., Ward, R.W., Eds.; pp. 275-281. Available at: http://scab.pw. usda.gov/pdfs/forum_02_proc.pdf\#page=288 (accessed on 15 August 2011).

17. Lee, Y.W.; Jeon, J.J.; Kim, H.; Jang, I.Y.; Kim, H.S.; Yun, S.H.; Kim, J.G. Lineage Composition and Trichothecene Production of Gibberella Zeae Population in Korea. In New Horizons of Mycotoxicology for Assuring Food Safety, Yoshizawa, T., Ed.; Kagawa, Japan, 2004; pp. 117-122.

18. Monds, R.D.; Cromey, M.G.; Lauren, D.R.; Marshall, J. Fusarium graminearum, F. cortaderiae and $F$. pseudograminearum in New Zealand: Molecular phylogenetic analysis, mycotoxin chemotypes and co-existence of species. Mycol. Res. 2005, 109, 410-420.

19. Roux, J.; Steenkamp, E.T.; Marasas, W.F.O.; Wingfield, M.J.; Wingfield, B.D. Characterization of Fusarium graminearum from Acacia and Eucalyptus using $\beta$-tubulin and histone gene sequences. Mycologia 2001, 93, 704-711.

20. Ward, T.J.; Clear, R.M.; Rooney, A.P.; O’Donnell, K.; Gaba, D.; Patrick, S.; Starkey, D.E.; Gilbert, J.; Geiser, D.M.; Nowicki, T.W. An adaptive evolutionary shift in Fusarium head blight pathogen populations is driving the rapid spread of more toxigenic Fusarium graminearum in North America. Fungal Genet. Biol. 2008, 45, 473-484.

21. Zhang, J.B.; Li, H.P.; Dang, F.J.; Qu, B.; Xu, Y.B.; Zhao, C.S.; Liao, Y.C. Determination of the trichothecene mycotoxin chemotypes and associated geographical distribution and phylogenetic species of the Fusarium graminearum clade from China. Mycol. Res. 2007, 111, 967-975.

22. Yang, L.; van der Lee, T.; Yang, X.; Yu, D.; Waalwijk, C. Fusarium populations on Chinese barley show a dramatic gradient in mycotoxin profiles. Phytopathology 2008, 98, 719-727.

23. Zhang, H.; Zhang, Z.; Van der Lee, T.; Chen, W.Q.; Xu, J.; Xu, J.S.; Yang, L.; Yu, D.; Waalwijk, C.; Feng, J. Population genetic analyses of Fusarium asiaticum populations from barley suggest a recent shift favoring 3ADON producers in southern China. Phytopathology 2010, 100, 328-336.

24. Zhang, Z.; Zhang, H.; Van der Lee, T.; Chen, W.Q.; Arens, P.; Xu, J.; Xu, J.S.; Yang, L.J.; Yu, D.Z.; Waalwijk, C.; Feng, J. Geographic substructure of Fusarium asiaticum isolates collected from barley in China. Eur. J. Plant Pathol. 2010, 127, 239-248. 
25. Gale, L.R.; Harrison, S.A.; Ward, T.J.; O’Donnell, K.; Milus, E.A.; Gale, S.W.; Kistler, H.C. Nivalenol-type populations of Fusarium graminearum and $F$. asiaticum are prevalent on wheat in southern Louisiana. Phytopathology 2011, 101, 124-134.

26. Bowden, R.L.; Leslie, J.F. Diversity of Gibberella zeae at small spatial scales. Phytopathology 1994, 84, 1140.

27. Bowden, R.L.; Leslie, J.F. Sexual recombination in Gibberella zeae. Phytopathology 1999, 89, $182-188$.

28. Carter, J.P.; Rezanoor, H.N.; Desjardins, A.E.; Nicholson, P. Variation in Fusarium graminearum isolates from Nepal associated with their host of origin. Plant Pathol. 2000, 49, 1-10.

29. Carter, J.P.; Rezanoor, H.N.; Holden, D.; Desjardins, A.E.; Plattner, R.D.; Nicholson, P. Variation in pathogenicity associated with the genetic diversity of Fusarium graminearum. Eur. J. Plant Pathol. 2002, 108, 573-583.

30. Gale, L.R.; Chen, L.F.; Hernick, C.A.; Takamura, K.; Kistler, H.C. Population analysis of Fusarium graminearum from wheat fields in eastern China. Phytopathology 2002, 92, 1315-1322.

31. Miedaner, T.; Schilling, A.G.; Geiger, H.H. Molecular genetic diversity and variation for aggressiveness in populations of Fusarium graminearum and Fusarium culmorum sampled from wheat fields in different countries. J. Phytopathol. 2001, 149, 641-648.

32. Ward, T.J.; Bielawski, J.P.; Kistler, H.C.; Sullivan, E.; O’Donnell, K. Ancestral polymorphism and adaptive evolution in the trichothecene mycotoxin gene cluster of phytopathogenic Fusarium. Proc. Natl. Acad. Sci. USA 2002, 99, 9278-9283.

33. Zeller, K.A.; Bowden, R.L.; Leslie, J.F. Diversity of epidemic populations of Gibberella zeae from small quadrats in Kansas and North Dakota. Phytopathology 2003, 93, 874-880.

34. Onyike, N.B.N.; Nelson, P.E. Fusarium species associated with millet grain from Nigeria, Lesotho, and Zimbabwe. Mycologia 1991, 83, 708-712.

35. Muthomi, J.W.; Ndung'u, J.K.; Gathumbi, J.K.; Mutitu, E.W.; Wagacha, J.M. The occurrence of Fusarium species and mycotoxins in Kenyan wheat. Crop Prot. 2008, 27, 1215-1219.

36. Wagacha, J.M.; Steiner, U.; Dehne, H.-W.; Zuehlke, S.; Spiteller, M.; Muthomi, J.; Oerke, E.-C. Diversity in mycotoxins and fungal species infecting wheat in Nakuru district, Kenya. J. Phytopathol. 2010, 158, 527-535.

37. Boutigny, A.-L.; Ward, T.J.; Van Coller, G.J.; Flett, B.; Lamprecht, S.C.; O’Donnell, K.; Viljoen, A. Analysis of the Fusarium graminearum species complex from wheat, barley, and maize in South Africa provides evidence of species-specific differences in host preference. Fungal Genet. Biol. 2011, 48, 914-920.

38. Zeller, K.A.; Bowden, R.L.; Leslie, J.F. Population differentiation and recombination in wheat scab populations of Gibberella zeae from the United States. Mol. Ecol. 2004, 13, 563-571.

39. Geraldo, M.R.F.; Tessmann, D.J.; Kemmelmeier, C. Production of mycotoxins by Fusarium graminearum isolated from small cereals (wheat, triticale and barley) affected with scab disease in Southern Brazil. Braz. J. Microbiol. 2006, 37, 58-63.

40. Fernando, W.G.D.; Zhang, J.X.; Dusabenyagasani, M.; Guo, X.W.; Ahmed, H.; McCallum, B. Genetic diversity of Gibberella zeae isolates from Manitoba. Plant Dis. 2006, 90, 1327-1342. 
41. Ramirez, M.L.; Reynoso, M.M.; Farnochi, M.C.; Torres, A.M.; Leslie, J.F.; Chulze, S.N. Population genetic structure of Gibberella zeae isolated from wheat in Argentina. Food Addit. Contam. 2007, 24, 1115-1120.

42. Gale, L.R.; Ward, T.J.; Balmas, V.; Kistler, H.C. Population subdivision of Fusarium graminearum sensu stricto in the Upper Midwestern United States. Phytopathology 2007, 97, 1434-1439.

43. Scoz, L.B.; Astolfi, P.; Reartes, D.S.; Schmale, D.G., III; Moraes, M.G.; Del Ponte, E.M. Trichothecene mycotoxin genotypes of Fusarium graminearum sensu stricto and Fusarium meridionale in wheat from Southern Brazil. Plant Pathol. 2009, 58, 344-351.

44. Alvarez, C.L.; Azcarate, M.P.; Pinto, V.F. Toxigenic potential of Fusarium graminearum sensu stricto isolates from wheat in Argentina. Int. J. Food Microbiol. 2009, 135, 131-135.

45. Sampietro, D.A.; Marín, P.; Iglesias, J.; Presello, D.A.; Vatuone, M.A.; Catalan, C.A.N.; Gonzalez Jaen, M.T. A molecular based strategy for rapid diagnosis of toxigenic Fusarium species associated to cereal grains from Argentina. Fungal Biol. 2010, 114, 74-81.

46. Sampietro, D.A.; Díaz, C.G.; Gonzalez, V.; Vattuone, M.A.; Ploper, L.D.; Catalan, C.A.; Ward, T.J. Species diversity and toxigenic potential of Fusarium graminearum complex isolates from maize fields in northwest Argentina. Int. J. Food Microbiol. 2011, 145, 359-364.

47. Reynoso, M.M.; Ramirez, M.L.; Torres, A.M.; Chulze, S.N. Trichothecene genotypes and chemotypes in Fusarium graminearum strains isolated from wheat in Argentina. Int. J. Food Microbiol. 2011, 145, 444-448.

48. Astolfi, P.; Dos Santos, J.; Schneider, L.; Gomes, L.B.; Silva, C.N.; Tessmann, D.J.; Del Ponte, E.M. Molecular survey of trichothecene genotypes of Fusarium graminearum species complex from barley in southern Brazil. Int. J. Food Microbiol. 2011, 148, 197-201.

49. Astolfi, P.; Reynoso, M.M.; Ramirez, M.L.; Chulze, S.N.; Alves, T.C.A.; Tessmann, D.J.; Del Ponte, E.M. Genetic population structure and trichothecene genotypes of Fusarium graminearum isolated from wheat in southern Brazil. Plant Pathol. 2011, doi:10.1111/j.1365-3059.2011.02515.X.

50. Gagkaeva, T.Y.; Yli-Mattila, T. Genetic diversity of Fusarium graminearum in Europe and Asia. Eur. J. Plant Pathol. 2004, 110, 550-562.

51. Ji, L.; Cao, K.; Wang, S. Determination of deoxynivalenol and nivalenol chemotypes of Fusarium graminearum from China by PCR assay. J. Phytopathol. 2007, 155, 505-512.

52. Suga, H.; Karugia, G.W.; Ward, T.; Gale, L.R.; Tomimura, K.; Nakajima, T.; Miyasaka, A.; Koizumi, S.; Kageyama, K.; Hyakumachi, M. Molecular characterization of the Fusarium graminearum species complex in Japan. Phytopathology 2008, 98, 159-166.

53. Haratian, M.; Sharifnabi, B.; Alizadeh, A.; Safaie, N. PCR analysis of the Tril3 gene to determine the genetic potential of Fusarium graminearum isolates from Iran to produce nivalenol and deoxynivalenol. Mycopathologia 2008, 166, 109-116.

54. Lee, J.; Chang, I.Y.; Kim, H.; Yun, S.H.; Leslie, J.; Lee, Y.W. Genetic diversity and fitness of Fusarium graiminearum populations from rice in Korea. Appl. Environ. Microbiol. 2009, 75, 3289-3295. 
55. Karugia, G.W.; Suga, H.; Gale, L.R.; Nakajima, T.; Ueda, A.; Hyakumachi, M. Population structure of Fusarium asiaticum from two Japanese regions and eastern China. J. Gen. Plant Pathol. 2009, 75, 110-118.

56. Karugia, G.W.; Suga, H.; Gale, L.R.; Nakajima, T.; Tomimura, K.; Hyakumachi, M. Population structure of the Fusarium graminearum species complex from a single Japanese wheat field sampled in two consecutive years. Plant Dis. 2009, 93, 170-174.

57. Lee, S.-H.; Lee, J.; Nam, Y.J.; Lee, S.; Ryu, J.-G.; Lee, T. Population Structure of Fusarium graminearum from maize and rice in 2009 in Korea. Plant Pathol. 2010, 26, 321-327.

58. Waalwijk, C.; Kastelein, P.; de Vries, I.; Kerenyi, Z.; van der Lee, T.; Hesselink, T.; Köhl, J.; Kema, G. Major changes in Fusarium spp. in wheat in the Netherlands. Eur. J. Plant Pathol. 2003, 109, 743-754.

59. Láday, M.; Juhász, Á.; Mulè, G.; Moretti, A.; Szécsi, Á.; Logrieco, A. Mitochondria DNA diversity and lineage determination of European isolates of Fusarium graminearum (Gibberella zeae). Eur. J. Plant Pathol. 2004, 110, 545-550.

60. Tóth, B.; Mesterházy, Á.; Horváth, Z.; Bartók, T.; Varga, M.; Varga, J. Genetic variability of central European isolates of the Fusarium graminearum species complex. Eur. J. Plant Pathol. 2005, 113, 35-45.

61. Sayer, S.T.; Lauren, D.R. Fusarium infection in New Zealand grain. N. Z. J. Crop Hortic. Sci. 1991, 19, 143-148.

62. Lauren, D.R.; Sayer, S.T.; Di Menna, M.E. Trichothecene production by Fusarium species isolated from grain and pasture throughout New Zealand. Mycopathologia 1992, 120, 167-176.

63. Akinsanmi, O.A.; Backhouse, D.; Simpfendorfer, S.; Chakraborty, S. Genetic diversity of Australian Fusarium graminearum and F. pseudograminearum. Plant Pathol. 2006, 55, 494-504.

64. Wright, D.G.; Thomas, G.J.; Loughman, R.; Fuso-Nyarko, J.; Bullock, S. Detection of Fusarium graminearum in wheat grains in Western Australia. Australas. Plant Dis. Notes 2010, 5, 82-84.

65. Taylor, J.W.; Jacobson, D.J.; Kroken, S.; Kasuga, T.; Geiser, D.M.; Hibbett, D.S.; Fisher, M.C. Phylogenetic species recognition and species concepts in Fungi. Fungal Genet. Biol. 2000, 31, 21-32.

66. Desjardins, A.E.; Proctor, R.H. Genetic diversity and trichothecene chemotypes of the Fusarium graminearum clade isolated from maize in Nepal and identification of a putative new lineage. Fungal Biol. 2011, 115, 38-48.

67. Jeon, J.J.; Kim, H.; Kim, H.S.; Zeller, K.A.; Lee, T.; Yun, S.H.; Bowden, R.L.; Leslie, J.F.; Lee, Y.W. Genetic diversity of Fusarium graminearum from maize in Korea. Fungal Genet. Newsl. 2003, 50, S142.

68. Miller, J.D.; Greenhalgh, R.; Wang, Y.Z.; Lu, M. Trichothecene chemotypes of three Fusarium species. Mycologia 1991, 83, 121-130.

69. Moss, M.O.; Thrane, U. Fusarium taxonomy with relation to trichothecene formation. Toxicol. Lett. 2004, 153, 23-28.

70. Goswami, R.S.; Kistler, H.C. Pathogenicity and in planta mycotoxin accumulation among members of the Fusarium graminearum species complex on wheat and rice. Phytopathology 2005, 95, 1397-1404. 
71. Desjardins, A.E.; Busman, M.; Manandhar, G.; Jarosz, A.M.; Manandhar, H.K.; Proctor, R.H. Distribution of the mycotoxins nivalenol and deoxynivalenol in naturally and experimentally infected maize. J. Agric. Food Chem. 2008, 56, 5428-5436.

72. Jennings, P.; Coates, M.E.; Walsh, K.; Turner, J.A.; Nicholson, P. Determination of deoxynivalenol- and nivalenol-producing chemotypes of Fusarium graminearum isolated from wheat crops in England and Wales. Plant Pathol. 2004, 53, 643-652.

73. Talas, F.; Parzies, H.K.; Miedaner, T. Diversity in genetic structure and chemotype composition of Fusarium graminearum sensu stricto populations causing wheat head blight in individual fields in Germany. Eur. J. Plant Pathol. 2011, 1, 39-48.

74. Pasquali, M.; Giraud, F.; Brochot, C.; Cocco, E.; Hoffmann, L.; Bohn, T. Genetic Fusarium chemotyping as a useful tool for predicting nivalenol contamination in winter wheat. Int. J. Food Microbiol. 2010, 137, 246-253.

75. Abramson, D.; Clear, R.M.; Smith, D.M. Trichothecene production by Fusarium spp. isolated from Manitoba grain. Can. J. Plant Pathol. 1993, 15, 147-152.

76. Abramson, D.; Clear, R.M.; Gaba, D.; Smith, D.M.; Patrick, S.K.; Saydak, D. Trichothecene and moniliformin production by Fusarium species from western Canadian wheat. J. Food Prot. 2001, $64,1220-1225$.

77. Guo, X.W.; Fernando, W.G.D.; Seow-Brock, H.Y. Population structure, chemotype diversity, and potential chemotype shifting of Fusarium graminearum in wheat fields of Manitoba. Plant Dis. 2008, 92, 756-762.

78. Schmale, D.G., III; Wood-Jones, A.K.; Cowger, C.; Bergstrom, G.C.; Arellano, C. Trichothecene genotypes of Gibberella zeae from winter wheat fields in the eastern USA. Plant Pathol. 2011, doi: 10.1111/j.1365-3059.2011.02443.x.

79. Burlakoti, R.R.; Ali, S.; Secor, G.A.; Neate, S.M.; McMullen, M.P.; Adhikari, T.B. Genetic relationships among populations of Gibberella zeae from barley, wheat, potato, and sugar beet in the Upper Midwest of the United States. Phytopathology 2008, 98, 969-976.

80. Schmale, D.G., III; Leslie, J.F.; Zeller, K.A.; Saleh, A.A.; Shields, E.J.; Bergstrom, G.C. Genetic structure of atmospheric populations of Gibberella zeae. Phytopathology 2006, 96, 1021-1026.

81. Qu, B. Genetic Diversity of Fusarium Graminearum in China and its Comparison with the Isolates from of Nepal, Europe, and USA. PhD thesis, Hauzhong Agricultural University, Wuhan, China, September 2002.

82. Narayanasamy, P. Molecular Biology in Plant Pathogenesis and Disease Management: Microbial Plant Pathogens, 1st ed.; Springer: New York, NY, USA, 2008; Volume 1, pp. 175-178.

83. Dusabenyagasani, M.; Dostaler, D.; Hamelin, R.C. Genetic diversity among Fusarium graminearum strains from Ontario and Quebec. Can. J. Plant Pathol. 1999, 21, 308-314.

84. Liu, W.-C.; Xi, J.-H.; Li, H.-Y.; Pan, H.-Y.; Hu, H.-Q.; Guo, Y.-L.; Bai, R.-L. RAPD analysis of isolates from Fusarium spp. causing wheat head blight in northeast China. Mycosystema 2002, $21,63-70$.

85. Quellet, T.; Seifert, K.A. Genetic characterization of Fusarium graminearum strains using RAPD and PCR amplification. Phytopathology 1993, 83, 1003-1007. 
86. Busso, C.; Kaneshima, E.N.; De Assis Franco, F.; Querol, C.B.; De Castro-Prado, M.A. Vegetative compatibility and molecular characterization of Fusarium graminearum isolates from the State of Paraná, Brazil. Cienc. Rural. 2007, 37, 1813-1816.

87. Riedy, M.F.; Hamilton, W.J.; Aquadro, C.F. Excess non-parental bands in offspring from known pedigrees assayed using RAPD PCR. Nucleic Acid Res. 1992, 20, 918.

88. Williams, J.G.; Kubelik, A.R.; Livak, K.J.; Rafalski, J.A.; Tingey, S.V. DNA polymorphisms amplified by arbitrary primers are useful as genetic markers. Nucleic Acids Res. 1990, 18, 6531-6535.

89. Blears, M.J.; de Grandis, S.A.; Lee, H.; Trevors, J.T. Amplified fragment length polymorphism (AFLP): A review of the procedure and its applications. J. Ind. Microbiol. Biotechnol. 1998, 21, 99-114.

90. Leissner, C.E.W.; Niessen, M.L.; Vogel, R.F. Use of the AFLP technique for the identification and discrimination of Fusarium graminearum. Cer. Res. Com. 1997, 25, 555-556.

91. Abd-Elsalam, K.A.; Schnieder, F.; Verreet, J.A. Population analysis of Fusarium species. Phytomedizin 2002, 3, 18-19.

92. Kiprop, E.K.; Baudoin, J.P.; Mwangombe, A.W.; Kimani, P.M.; Mergeai, G.; Maquet, A. Characterization of Kenyan isolates of Fusarium udum from Pigeonpea [Cajanus cajan (L.) Millsp.] by cultural characteristics, aggressiveness and AFLP analysis. J. Phytopathol. 2002, $150,517-527$.

93. Sivaramakrishnan, S.; Kannan, S.; Singh, S.D. Genetic variability of Fusarium wilt pathogen isolates of chickpea (Cicer arietinum L.) assessed by molecular markers. Mycopathologia 2002, 155, 171-178.

94. Bowden, R.L.; Zeller, K.A.; Leslie, J.F. Population structure of Gibberella zeae in the Great Plains of North America. In Proceedings of the International Symposium on Wheat Improvement for Scab Resistance, Suzhou and Nanjing, Jiangsu, China, 2000; pp. 211-213.

95. Majer, D.; Lewis, B.G.; Mithen, R. Genetic variation among field isolates of Pyrenopeziza brassicae. Plant Pathol. 1998, 47, 22-28.

96. O’Donnell, K.; Sutton, D.A.; Rinaldi, M.G.; Magnon, K.C.; Cox, P.A.; Revankar, S.G.; Sanche, S.; Geiser, D.M.; Juba, J.H.; van Burik, J.-A.H.; Padhye, A.; Anaissie, E.J.; Francesconi, A.; Walsh, T.J.; Robinson, J.S. Genetic diversity of human pathogenic members of the Fusarium oxysporum complex inferred from multilocus DNA sequence data and amplified fragment length polymorphism analyses: Evidence for the recent dispersion of a geographically widespread clonal lineage and nosocomial origin. J. Clin. Microbiol. 2004, 42, 5109-5120.

97. Li, G.; Quiros, C.F. Sequence related amplified polymorphism (SRAP), a new system based on a simple PCR reaction: Its application to mapping and gene tagging in Brassica. Theor. Appl. Genet. 2001, 103, 455-461.

98. Mishra, P.K.; Tewari, J.P.; Clear, R.M.; Turkington, T.K. Molecular genetic variation and geographical structuring in Fusarium graminearum. Ann. Appl. Biol. 2004, 145, 299-307.

99. Cuomo, C.A.; Güldener, U.; Xu, J.R.; Trail, F.; Turgeon, B.G.; Pietro, A.D.; Walton, J.D.; Ma, L.J.; Baker, S.E.; Rep, M.; et al. The Fusarium graminearum genome reveals a link between localized polymorphism and pathogen specialization. Science 2007, 317, $1400-1402$. 
100. Burlakoti, R.R.; Neate, S.M.; Adhikari, T.B.; Gyawali, S.; Salas, B.; Steffenson, B.J.; Schwarz, P.B. Trichothecene profiling and population genetic analysis of Gibberella zeae from barley in North Dakota and Minnesota. Phytopathology 2011, 101, 687-695.

101. Kimura, M.; Tokai, T.; Takahashi-Ando, N.; Ohsato, S.; Fujimura, M. Molecular and genetic studies of Fusarium trichothechne biosynthesie: Pathways, genes, and evolution. Biosci. Biotechnol. Biochem. 2007, 71, 2105-2123.

102. Suga, H.; Gale, L.R.; Kistler, H.C. Development of VNTR markers for two Fusarium graminearum clade species. Mol. Ecol. Notes 2004, 4, 468-470.

103. Giraud, T.; Fournier, E.; Vautrin, D.; Solignac, M.; Vercken, E.; Bakan, B.; Brygoo, Y. Isolation of eight polymorphic microsatellite loci, using an enrichment protocol, in the phytopathogenic fungus Fusarium culmorum. Mol. Ecol. Notes 2002, 2, 121-123.

104. Francis, R.G.; Burgess, L.W. Characteristics of two populations of Fusarium roseum "Graminearum" in eastern Australia. Trans. Br. Mycol. Soc. 1977, 68, 421-427.

105. Benyon, F.H.L.; Burgess, L.W.; Sharp, P.J. Molecular genetic investigations and reclassification of Fusarium species in sections Fusarium and Roseum. Mycol. Res. 2000, 104, 1164-1174.

106. Aoki, T.; O'Donnell, K. Morphological and molecular characterization of Fusarium pseudograminearum sp. nov., formerly recognised as the group 1 population of $F$. graminearum. Mycologia 1999, 91, 597-609.

107. Láday, M.; Bagi, F.; Mesterházy, A.; Szécsi, Á. Isozyme evidence for two groups of Fusarium graminearum. Mycol. Res. 2000, 104, 788-793.

(C) 2011 by the authors; licensee MDPI, Basel, Switzerland. This article is an open access article distributed under the terms and conditions of the Creative Commons Attribution license (http://creativecommons.org/licenses/by/3.0/). 